\title{
MAMÃO, UMA HISTÓRIA DE SUCESSO ${ }^{1}$
}

\author{
CARLOS RUGGIERO ${ }^{2}$, SERGIO LÚCIO DAVID MARIN ${ }^{3}$, JOSÉ FERNANDO DURIGAN ${ }^{4}$
}

\section{HISTÓRICO}

A literatura mundial, em várias ocasiões, enfatiza que "a necessidade é mãe de todas as grandes mudanças". O que procuraremos mostrar é que este fato também ocorreu na cultura do mamoeiro no Brasil, que, atualmente, ocupa uma área de cerca de 36,5 mil hectares, sendo considerado o maior produtor mundial. Assim, abordaremos, neste capítulo, a evolução da cultura desde sua introdução na região de Monte Alto-SP, que já foi considerada a capital brasileira do mamão, até a sua consolidação nos Estados da Bahia, Espírito Santo, Rio Grande do Norte e Ceará, atualmente considerados como os maiores produtores nacionais (SERRANO; CATTANEO, 2010).

Fazendo uma análise retrospectiva da cultura do mamoeiro no País, desde meados do século XX até hoje, verificaremos que mudanças altamente significativas ocorreram, indiscutivelmente alicerçadas pela pesquisa, as quais fizeram com que deixássemos de produzir frutas somente para atender ao mercado nacional para se transformar, além do maior produtor, também no segundo maior exportador mundial. Assim, verificou-se, a partir do início da década de 90, um crescente aumento nas exportações brasileiras de papaya, culminando, em 2008, com um volume de cerca de 30 mil toneladas, gerando uma receita de US\$38,6 milhões (SERRANO; CATTANEO, 2010). Vale ressaltar que passamos a produzir frutos de alta qualidade tanto para as variedades de mamão pertencentes ao grupo 'Solo' (frutas pequenas) quanto para as cultivares do grupo 'Formosa' (frutas maiores), em que pese estes últimos serem oriundos de sementes híbridas importadas (SERRANO; CATTANEO, 2010).

Na cultura do mamoeiro, em nossa opinião, alguns dos seguintes pontos foram fundamentais por proporcionarem condições para a busca de soluções, estimulando a pesquisa na área, fator que determinou uma mudança altamente significativa, obtendo, em razão destas conquistas, pomares com produtividade superior a $100 \mathrm{t} / \mathrm{ha}$.

\section{INÍCIO DA MIGRAÇÃO DA CULTURA NO BRASIL}

O primeiro ponto a estimular esta significativa mudança ocorreu em 1967, na região de Monte Alto-SP, quando foi relatada pela primeira vez no Brasil a ocorrência endêmica de uma doença virótica, denominada "mosaico do mamoeiro". A cidade era, na ocasião, considerada a capital brasileira do mamão e chegou, no auge da sua exploração, a enviar para o mercado cerca de 110 caminhões/dia, podendo-se avaliar o que representava a cultura para a economia da região naquela época (RUGGIERO et al., 2010).

No desespero de lutar contra o vírus do mosaico, verificou-se um processo migratório do mamoeiro para outras regiões agrícolas de São Paulo até o seu completo desaparecimento do Estado, em meados da década de 70 .

A partir de 1975/1976 a cultura migrou para outras regiões do País como o nordeste do Pará, extremo sul da Bahia e norte do Espírito Santo. Nessas regiões, graças ao aprendizado com os erros do passado, os técnicos e produtores passaram a executar rigorosos sistemas de prevenção, consistindo no corte e erradicação de plantas enfermas logo após os primeiros sintomas da doença. Essas medidas possibilitaram a estabilidade da cultura nestes estados por mais de 25 anos.

A partir da década de 80 , a migração da cultura ocorreu devido a razões muito mais comerciais do que fitossanitárias. Assim, a maior proximidade do mercado consumidor nacional determinou a difusão para a região de Inhumas- GO (1980), Petrolina- PE (1995), Ceará (1998) e Janaúba-MG (2001). Da mesma forma, a maior proximidade do mercado americano foi determinante para a expansão da cultura no Estado do Rio Grande do Norte, possibilitando o grande aumento das exportações marítimas de papaya para os Estados Unidos, verificado em fins da década de 90 .

A despeito da forte migração da cultura, um fato comercial marcante e curioso ocorreu nos anos 70 , notadamente nas principais centrais de abasteci-

\footnotetext{
${ }^{1}$ Palestra Sinfruit 215 - Simpósio Internacional de Fruticultura - Avanços na Fruticultura (17 a 21 Outubro)

${ }^{2}$ Prof. Emérito, FCAV/Unesp. ruggiero@fcav.unesp.br

${ }^{3}$ Rubisco Sementes - genética em papaya. sergio@rubiscosementes.com.br

${ }^{4}$ Prof. Titular, FCAV/Unesp, departamento de Tecnologia. jfduri@fcav.unesp.br
} 
mento e feiras livres de todo o País. Apesar de, nesse período, já não mais existir pomares de mamão no Estado de São Paulo, ainda assim prevaleceu durante quase toda uma década o slogan da famosa marca: "comprem o famoso mamão de Monte Alto".

\section{PRIMEIRAS INTRODUÇÕES DE SE- MENTES MELHORADAS E AVANÇOS NO MELHORAMENTO GENÉTICO}

Outro ponto catalisador destas mudanças ocorreu entre 1972/1973, quando se verificou no Brasil a importação das primeiras sementes da variedade 'Sunrise Solo' oriundas do Havai-EUA. Esta cultivar do grupo 'Solo', quando introduzida na região nordeste do Pará, apresentou elevada estabilidade e grande adaptabilidade às condições quentes e úmidas da região. Ressalta-se que a simples introdução da cultivar 'Sunrise Solo' provocou uma significativa expansão da comercialização do fruto, devido à sua grande aceitação, tanto no mercado nacional quanto no internacional (MARIN, informação pessoal, 2011).

Neste mesmo período, iniciaram-se, também, as importações de sementes híbridas dos mamoeiros do grupo 'Formosa', oriundas de Taiwan, de onde ainda são até hoje importadas (SERRANO; CATTANEO, 2010).

A partir de 1982, verificou-se, no Brasil, uma grande evolução no melhoramento genético do mamoeiro no tocante ao desenvolvimento de variedades do grupo 'Solo', que atendessem tanto à demanda do mercado nacional quanto internacional. Nesse sentido, foram introduzidas no mercado as seguintes variedades comerciais, com suas respectivas épocas de lançamento, fruto do contínuo trabalho das iniciativas públicas e privadas envolvidas no segmento do agronegócio do mamoeiro:

\subsection{1. 'Sunrise Solo 72/12' (1982) \\ 1.1.2. 'Baixinho de Santa Amália' (1986) \\ 1.1.3. 'Grampola' (1988) \\ 1.1.4. 'Golden (1996) \\ 1.1.5. 'Gran Golden' (1997) \\ 1.1.6. 'Sunrise Solo BSA' (1998) \\ 1.1.7. 'Golden MD 2' (2001) \\ 1.1.8. 'Golden THB' (2004)}

Há que se ressaltar, contudo, que o mesmo avanço não se verificou no programa de melhoramento genético no Brasil, visando à produção de híbridos nacionais como alternativa à importação de sementes oriundas de Taiwan. Assim, o híbrido 'Tainung 01 ', que foi introduzido no Brasil, no início da década de 70, continua, até o presente momento, predominando no mercado nacional dos mamoeiros do grupo 'Formosa'.

A despeito de os primeiros trabalhos com hibridação no Brasil terem sido iniciados na década de 70, através das pesquisas conjuntas do Dr. Dalmo Giacometti e Dr. Luna Uzeda, contudo, somente em 2001 foram lançadas e disponibilizadas no mercado sementes do primeiro híbrido nacional do grupo 'Formosa', fruto de parceria público-privada, denominado "Calimosa' e, mais recentemente, em 2011, foi lançada a público a primeira variedade do grupo 'Formosa', denominada 'Rubi Incaper 511'.

\section{PESQUISAS REALIZADAS E AÇÕES DE- SENVOLVIDAS PELA PARCERIA PÚBLICO- -PRIVADA}

As grandes âncoras estimuladoras do notável desenvolvimento da cultura do mamoeiro no Brasil, e em especial do melhoramento genético da cultura, devem ser creditadas à necessidade da constante luta em obter respostas aos seguintes pontos:

a) como lutar contra a doença do vírus do mosaico do mamoeiro?

b) como proporcionar aos produtores brasileiros sementes de ótima qualidade, com o ajuste nas técnicas de produção para altas produtividades?

c) como produzir frutas com qualidade para os mercados nacional e internacional?

Inegavelmente, essas conquistas foram frutos das condições básicas para os trabalhos de pesquisa que se desenvolveram no Brasil a partir da metade do século XX, por grupos que se formaram neste período.

Neste contexto, foi decisiva a participação da Universidade Estadual Paulista, UNESP, Câmpus de Jaboticabal-SP, que além do inúmero acervo de publicações técnico-científicas, realizou, em 1980 e 1988, os dois primeiros Simpósios Brasileiros sobre a cultura do mamoeiro. Ressalta-se que esses dois eventos, que contaram com a participação dos mais renomados pesquisadores nacionais e internacionais desta cultura, podem ser considerados como o marco introdutório do sucesso da implantação da cultura do mamoeiro ‘Solo' no Brasil.

A produção científica na área do mamão, das Instituições brasileiras que trabalham com pesquisa em fruticultura tropical, pode ser equiparada às das Universidades internacionais, algumas com mais de 400 anos. Devem ser considerados os trabalhos desenvolvidos pela Universidade do Hawaii, cujas publicações na década de 60 irradiaram a tecnologia para a cultura do mamoeiro pelo mundo (RUGGIERO, 2009). 
Inquestionavelmente, tem contado com o apoio dos estudantes, notadamente os da pós-graduação, que são um grande suporte, pois proporcionam mão de obra altamente qualificada e criativa. Vale destacar a opinião do Professor Dr. Henry Nakasone, da Hawaii University, cuja contribuição à cultura do mamoeiro é muito reconhecida e que esteve no Brasil participando dos dois primeiros simpósios sobre a cultura do mamoeiro, realizados na UNESP/ Jaboticabal. Nessas oportunidades, ele deixou dito uma grande verdade: "o estudante de pós-graduação se escraviza pelo sistema", justificando a valiosa contribuição destes colaboradores.

Outro ponto importante é a alocação de recursos para o desenvolvimento de pesquisas e tem sido basicamente financiada por instituições governamentais, com ênfase nas Universidades, nos Institutos e Empresas de Pesquisa, e nas Instituições financiadoras, com destaque para o CNPq, o FINEPE e as Fundações Estaduais, como a FAPESP, que alicerçou a criação de outras como a FAPERJ, a FAPEMIG (1985) e a FAPESB (2001), dentre outras.

A criação de fundos para o desenvolvimento é outra possibilidade que tem suportado a pesquisa em algumas culturas, como o FUNDECITRUS (1977), que proporciona um bom suporte à citricultura brasileira. O Fundo PASSIFLORA também vem servindo de suporte ao desenvolvimento da cultura do maracujazeiro, a despeito das dificuldades que encontra para seu melhor desempenho. Vale destacar, também, o trabalho de algumas associações, como a AGAPOMI (1979) e a ABPM (1978), que, embora com conotações diferentes dos fundos, exercem um papel importante para culturas específicas como a da maçã, bem como a criação da BRAPEX-ES (2001), que atua auxiliando na exportação de mamão.

A criação destes fundos, que ainda são poucos, precisa ser estimulada, pois além de darem um aval qualitativo às pesquisas prioritárias, pois contam com a participação de indústrias e produtores, seriam ferramentas importantes para o desenvolvimento de uma determinada frutífera. A cultura do mamoeiro ressente-se da falta de um fundo específico, pois além do suporte econômico estabelecerá prioridades para a pesquisa e ações que busquem soluções para a cultura, como os problemas de ordem fitossanitária (RUGGIERO, 2009).

\section{CONSERVAÇÃO PÓS-COLHEITA DO MAMÃO}

\subsection{INTRODUÇÃO}

Vários trabalhos destacam a importância da conservação da qualidade na comercialização do mamão, pois a maior parte desta fruta é consumida ao natural. Assim, a diminuição de suas perdas, que são bastante altas, e racionalizar sua distribuição e comercialização, tornam-se necessários ao conhecimento do comportamento pós-colheita desta fruta.

Os frutos do mamoeiro têm sido classificados quanto ao padrão respiratório como climatérios (WARDLAW; LEONARD, 1935; GARCIA, 1980), ou seja, podem amadurecer depois de colhidos. Nesta fruta, o índice respiratório é influenciado por fatores, tais como, temperatura e composição da atmosfera.

Esta fruta apresenta polpa delicada e saborosa, cujas características sensoriais (textura, cor e aroma), químicas (baixa acidez e bom equilíbrio entre açúcares e ácidos orgânicos) e digestivas, tornam esta fruta um alimento ideal e saudável para pessoas de todas as idades (MEDINA et al., 1980; FABI et al., 2010). De maneira geral, ela é consumida in natura, mas sua industrialização permite o aproveitamento integral do fruto e a oferta de extensa gama de produtos e subprodutos, que podem ser utilizados pelas indústrias de alimentos, farmacêuticas e de ração para animais (HINOJOSA; MONTGOMERY, 1988).

No seu amadurecimento, a temperatura exerce efeito direto, pois regula a velocidade com que as reações se processam a nível celular, e segundo a Lei de Van't Hoof pode aumentá-las na razão de 2,02,5 vezes, a cada $10^{\circ} \mathrm{C}$ de aumento. Teoricamente, o abaixamento na temperatura pode aumentar cada vez mais a vida pós-colheita dos frutos, não fosse o distúrbio fisiológico conhecido por "chilling", que se caracteriza por depressões na casca, amadurecimento comprometido, áreas aquosas na polpa e rápido desenvolvimento de microrganismos (CHITARRA; CHITARRA, 2005).

O ponto de colheita desta fruta depende, principalmente, do tempo necessário ao transporte desde o campo até o local de consumo, da estação do ano e da finalidade da produção (mercado externo, interno ou indústria). Basicamente, a colheita é realizada quando ele começa a formar listras amareladas (GAYET et al., 1995), que podem não estar correlacionadas com a constituição química da polpa e seu sabor.

Sua vida útil pode variar, principalmente com seu estádio de maturação e com a cultivar (BLEINROTH, 1988a), no entanto se observa que mamões colhidos no estádio indicado atingem as condições de consumo em uma semana, quando armazenados em condições ambientais (BRON, 2006; BRON; JACOMINO, 2006; FABI et al., 2007).

Como o mamão é uma fruta cujo teor de açúcares aumenta enquanto ligado à planta-mãe, algu- 
mas empresas deixam o fruto amadurecer na planta, o que exige cuidados no manuseio e uma cadeia de frio muito bem sincronizada, o que é divulgado nas caixas como "fruto amadurecido na planta" e é mais valorizado pelos consumidores, pois tem sabor mais doce.

\subsection{MOLÉSTIAS PÓS-COLHEITA}

Elas são responsáveis por grande parte das perdas que ocorrem na pós-colheita, principalmente como consequência do manuseio inadequado durante as operações de colheita, transporte, armazenamento e comercialização (VIDIGAL et al., 1979).

Entre as mais importantes, destaca-se a antracnose, causada pelo fungo Colletotrichum gloeosporioides Pez (BERGAMIN; KIMATI, 1980). O uso de fungicidas não tem possibilitado o controle eficiente desta podridão, o que tem levado ao uso de outros tratamentos, tais como o térmico (BLEINROTH, 1988b).

A possibilidade do uso do tratamento com água quente para controlar a antracnose foi descoberta em 1949, quando o Departamento de Fisiologia de Plantas da Universidade do Havaí, em cooperação com o Departamento de Agricultura dos Estados Unidos (USDA), estudava um processo para a desinfestação dos frutos que se destinavam a exportação. Tem-se recomendado a imersão dos frutos em água quente à $48^{\circ} \mathrm{C}$ por 20 minutos, à qual se adiciona fungicida, ou ainda a $54^{\circ} \mathrm{C}$ por 3 minutos. A casa de embalagem também deve ser constantemente desinfestada com cloro a 70-100 ppm, pH 6,0-7,5 (RIVETTI, 1992; GAYET et al.,1995).

O tratamento térmico do mamão, dentro da tecnologia utilizada para poder exportá-lo, é um procedimento utilizado pelas casas de embalagens no Brasil, pois é o fator que assegura a garantia de sanidade do mamão brasileiro no mercado exterior.

\subsection{DISTURBIOS FISIOLÓGICOS}

O mamão apresenta uma série de distúrbios fisiológicos que podem afetar sua qualidade pós-colheita, muitos dos quais determinados por fatores pré-colheita como tratos culturais e condições edafoclimaticas, ou fatores pós-colheita, como aquecimentos e frio usados inadequadamente.

Dentre estas, tem-se a mancha fisiológica do mamão, que foi mencionada pela primeira vez por Ishii e Holzmann (1963) em mamões cultivados no Havaí, as quais foram reconhecidas como desordem fisiológica, a partir dos trabalhos de Chan e Toh (1988). Campostrini et al. (2005) sugeriram que esta mancha poderia estar relacionada aos baixos teores de cálcio nos frutos, enquanto Oliveira et al. (2002), aos fatores nutricionais que antecedem a colheita. Gomes Filho et al. (2008) apontaram seu aspecto sazonal e relacionaram-na com as épocas de maior amplitude térmica.

Este problema é muito pouco conhecido e está a merecer pesquisas e trabalhos integrados para viabilizar seu controle a nível cientifico (GALLON, 2010).

\subsection{CONSERVAÇÃO PÓS-COLHEITA}

A temperatura do ambiente de conservação de mamões tem sido utilizadao para controlar o amadurecimento desta fruta. Vidolin (1984) armazenou frutos de mamão 'Sunrise-Solo', colhidos maturos ou com máximo desenvolvimento e coloração da casca verde-clara. Os armazenados a $30^{\circ} \mathrm{C}(94 \%$ UR $)$ conservaram-se por até 10 dias, mesmo tendo sido tratados termicamente $\left(49^{\circ} \mathrm{C}\right.$ por 20 minutos) e com a aplicação de fungicida, dado o desenvolvimento intenso de podridões. Frutos tratados, quando armazenados a $22,4^{\circ} \mathrm{C}(74 \% \mathrm{UR})$, tiveram vida útil de 15 dias, com baixa ocorrência de antracnose, enquanto os mantidos a $8,5^{\circ} \mathrm{C}(95-100 \% \mathrm{UR})$ apresentaram problemas com injúria pelo frio ou "chilling" em 17 dias.

Aumento no tempo de conservação desta fruta a $10^{\circ} \mathrm{C}$, que evita problemas com injúrias, mas permite a continuidade do seu amadurecimento, tem sido conseguido com o emprego de atmosfera controlada, com baixos níveis de $\mathrm{O}_{2}(1-5 \%)$. O mamão não tolera níveis de $\mathrm{CO}_{2}$ acima de 1-2\% (DELLA TOGNA, 1987; RIVETTI, 1992; MOSCA, 1992; GAYET et al., 1995; JACOMINO et al., 2002; CERQUEIRA-PEREIRA, 2009).

A pequena resistência do mamão ao armazenamento pós-colheita e sua suscetibilidade a temperaturas abaixo de $10^{\circ} \mathrm{C}$ e a ambiente com concentrações de $\mathrm{CO}_{2}$ acima de $1 \%$, têm feito com que se tenha procurado reduzir o tempo de viagem por navios no percurso entre o Brasil e a Europa ou América do Norte, plantando mamão no Estado do Rio Grande do Norte, o que reduz o tempo de viagem de 21-23 dias para 16-18 dias.

O mamão papaia é uma fruta apreciada pela cor vermelha da polpa e sabor adocicado (GOMEZ et al., 1999; 2002). Este mamão é uma fruta climatérica, com picos de produção do etileno e de $\mathrm{CO}_{2}$ durante o amadurecimento (FABI et al., 2007). Contudo, sua produção é afetada pelas perdas pós-colheita decorrentes do excessivo amolecimento da polpa, que favorece o ataque microbiano e os danos mecânicos. 
Vários estudos concentram-se nas modificações químicas das paredes celulares do mamão durante seu amadurecimento (MANRIQUE; LAJOLO, 2002; 2004; SHIGA et al., 2009). Fabi et al. (2009a; 2009b) isolaram uma sequência de cDNA de uma endopoligalacturonase (endoPG) de mamão papaia. Os estudos da expressão gênica e da atividade enzimática sugeriram uma relação direta entre o aumento de transcritos e atividade da enzima endoPG e a diminuição da firmeza da polpa durante o amadurecimento.

$\mathrm{O}$ tratamento do mamão com 1-metilciclopropeno (1-MCP) pareceu ter inibido a enzima endoPG, $\mathrm{e}$, consequentemente, a polpa não amoleceu (FABI et al., 2007, 2009b). A redução na despolimerização da parede celular em frutos tratados com 1-MCP corroborou os resultados observados (SHIGA et al., 2009).

Os estudos atuais abrangem a comparação do perfil de transcritos (transcriptoma) e de proteínas (proteômica) de frutos verdes com frutos maduros. Para tanto, algumas técnicas como $c D N A-A F L P$, Microarray, eletroforese bidimensional de proteínas, clonagem e expressão de proteínas e western blotting estão sendo utilizadas (NASCIMENTO et al., 2008).

Estudos de interação planta-patógeno também estão sendo investigados, através da interação de proteínas endógenas do mamão papaia que inibem a ação de poligalacturonases de fungos. Dessa maneira, através dos estudos já finalizados e dos estudos em andamento, busca-se relacionar a expressão de alguns genes de enzimas-chave com as propriedades adquiridas durante o amadurecimento do mamão papaia e que possam afetar, principalmente, a vida de prateleira e a qualidade final do fruto.

\subsection{PROCESSAMENTO MÍNIMO}

A Associação Internacional de Produtos Minimamente Processados (IFPA) define os Produtos Minimamente Processados como frutas ou hortaliças que são modificadas fisicamente, mas que mantêm o seu estado fresco (CANTWELL, 2000). Assim, é um produto fresco, tornado conveniente, com qualidade e garantia de sanidade (DURIGAN, 2000).

A possibilidade de processamento deste produto nas regiões produtoras tem contribuído para a diversificação das indústrias regionais, reduzindo as perdas pós-colheita, melhorando o manejo dos resíduos, facilitando o transporte e eliminando problemas de ordem fitossanitária. Além disso, esta nova opção aos produtores agrícolas permite maior aproveitamento da produção, agrega valor aos produtos, é bastante adequada às micro e pequenas empresas familiares e possibilita a fixação da mão de obra nas regiões produtoras (DURIGAN, 2000).

Este setor cresceu significativamente, abrindo espaço para se ampliar as possibilidades de comercialização do mamão e outras frutas, com valor agregado relativamente alto (TEIXEIRA et al., 2001; SARZI, 2002).

\section{REFERÊNCIAS}

BERGAMIN, F. A.; KIMATI, H. Doenças do mamoeiro - Carica papaya. In: Galli, F. et al. Manual de fitopatologia: doenças de plantas cultivadas. São Paulo: Ceres, 1980. p.338-346.

BLEINROTH, E.W. Determinação do ponto de colheita dos frutos. In BLEINROTH, E.W. Tecnologia de pós-colheita de frutas tropicais. Campinas: ITAL, 1988a. p. 1-19.

BLEINROTH, E.W. Preparo das frutas para comercialização e frigo-conservação. In BLEINROTH, E.W. Tecnologia de pós-colheita de frutas tropicais. Campinas: ITAL, 1988b. p. 51-64.

BRON, I. U. Amadurecimento do mamão 'Golden': ponto de colheita, bloqueio da ação do etileno e armazenamento refrigerado. 2006. 66f. Tese (Doutorado em Fitotecnia)- Escola Superior de Agricultura Luiz de Queiroz, Universidade de São Paulo, Piracicaba, 2006.

BRON, I. U.; JACOMINO, A. P. Ripening and quality of 'Golden' papaya fruit harvested at different maturity stages. Brazilian Journal of Plant Physiology, Londrina, v.18, n.3, p.389-396, 2006.

CAMPOSTRINI, E.; LIMA, H. C.; OLIVEIRA, J. G. de; MONNERAT, P. H.; MARINHO, C. S. Teores de $\mathrm{Ca}$ e variáveis meteorológicas: relações com a incidência da mancha fisiológica do mamão no norte fluminense. Bragantia, Campinas, v.64, n.4, p.601-613, 2005.

CANTWELL, M. The dynamic fresh-cut sector of the horticultural industry. In: ENCONTRO NACIONAL SOBRE PROCESSAMENTO MÍNIMO DE FRUTAS E HORTALIÇAS, 2., 2000. Viçosa. Palestras... Viçosa: UFV, 2000. p.147-155. 
CERQUEIRA-PEREIRA, E. C. Caracterização e comparação de sistemas de embalagem e transporte de mamão 'Solo' destinado ao mercado nacional. 2009. 114f. Tese. (Doutorado em Fitotecnia) - Escola Superior de Agricultura Luiz de Queiroz, Universidade de São Paulo, Piracicaba, 2009.

CHAN, Y. K.; TOH, W. K. Resistance to papaya fruit freckles among three breeding lines and their hybrids. Mardi Research Journal, Malasia, v.16, p.103-107, 1988.

CHITARRA, M. I. F.; CHITARRA, A. B. Pós-colheita de frutos e hortaliças: fisiologia e manuseio. 2. ed. Lavras: Ed. UFLA, 2005. 785p.

DELLA TOGNA, C. dos R. Conservação pós-colheita de mamões (Carica papaya $L_{\text {.) }}$, da cultivar Sunrise-Solo. 1987. 55f. Monografia (Graduação em Agronomia) - Faculdade de Ciências Agrárias e Veterinárias, Universidade Estadual Paulista, Jaboticabal, 1987.

DURIGAN, J.F. O processamento mínimo de frutas. In: CONGRESSO BRASILEIRO DE FRUTICULTURA, 16., 2000, Fortaleza. Palestra... Fortaleza: Sociedade Brasileira de Fruticultura, 2000. 12p.

FABI, J.P.; PERONI, F.H.G.; GOMEZ, M.L.P.A. Papaya, mango and guava fruit metabolism during ripening: postharvest changes affecting tropical fruit nutritional content and quality. Fresh Produce, v. 1, p. 56-66, 2010.

FABI, J.P.; LAJOLO, F.M.; NASCIMENTO, J.R.O. Cloning and characterization of transcripts differentially expressed in the pulp of ripening papaya. Scientia Horticulturae, Amsterdam, v. 121, p. 159-165, 2009a.

FABI, J.P.; CORDENUNSI, B.R.; SEYMOUR, G.B.; LAJOLO, F.M.; NASCIMENTO, J.R.O. Molecular cloning and characterization of a ripening-induced polygalacturonase related to papaya fruit softening. Plant Physiology and Biochemistry, Paris, v. 47, p. 1075-1081, 2009b.

FABI, J. P.; CORDENUNSI, B. R.; BARRETO, G. P. M.; MERCADANTE, A. Z.; LAJOLO, F. M.; NASCIMENTO, J. R. do. Papaya fruit ripening: response to ethylene and 1-methylciclopropene. Journal of Agricultural and Food Chemistry, Washington, v.55, p.6118-6123, 2007.
GALLON, C. Z. Amolecimento precoce da polpa e sua relação com as modificações da parede celular em mamões 'Golden'. 2010. 111f. Tese (Doutorado em Fisiologia e Bioquimica de Plantas) - Escola Superior de Agricultura Luiz de Queiroz, Universidade de São Paulo, Piracicaba, 2010.

GARCIA, L.L. Fisiologia de pós-colheita, maturação controlada, armazenamento e transporte de mamão. SIMPÓSIO BRASILEIRO SOBRE A CULTURA DO MAMOEIRO, 1. Jaboticabal, 1980. Anais... Piracicaba: Livroceres, 1980. p.253-260.

GAYET, J. P.; BLEINROTH, E. W.; MATALLO, M.; GARCIA, E. E. C.; GARCIA, A. E.; ARDITO, E. F. G.; BORDIN, M. R. Mamão para exportação: procedimentos de colheita e pós-colheita. Brasília: FRUPEX, Embrapa-SPI, 1995. 38p.

GOMEZ, M.L.P.A.; LAJOLO, F.M.; CORDENUNSI, B.R. Evolution of soluble sugars during ripening of papaya fruit and its relation to sweet taste. Journal of Food Science, Chicago, v. 67, p. 442-447, 2002.

GOMEZ, M.L.P.A.; LAJOLO, F.M.; CORDENUNSI, B.R. Metabolismo de carboidratos durante o amadurecimento do mamão (Carica papaya L. cv. Solo): influência da radiação gama. Ciência e Tecnologia de Alimentos, Campinas, v. 19, p. 246-252, 1999.

GOMES FILHO, A.; OLIVEIRA, J. G. de; VIANA, A. P.; PEREIRA, M. G. Mancha fisiológica e produtividade do mamão 'Tainung 01 ': efeito da lâmina de irrigação e cobertura do solo. Ciência e Agrotecnologia, Lavras, v.32, n.4, p.1161-1167, 2008.

HINOJOSA, R. L.; MONTGOMERY, M. W. Industrialização do mamão. Aspectos bioquímicos e tecnológicos da produção de purê asséptico. In: RUGGIERO, C. (Ed.). Mamão. Jaboticabal: FCAVUNESP, 1988. p.89-110.

ISHII, M.; HOLTZMANN, O. V. Papaya mosaic disease in Hawaii. Plant Disease Report, St. Paul, v.47, p.947-951, 1963.

JACOMINO, A. P.; KLUGE, R A.; BRACKMAN, A.; CAMARGO e CASTRO, P.R. Amadurecimento e senescência de mamão com 1-metilciclopropeno. Scientia Agricola, Piracicaba, v.59, n.2, p.303-308, 2002. 
MANRINQUE, G.D.; LAJOLO, F.M. Cell-wall polysaccharide modifications during postharvest ripening of papaya fruit (Carica papaya). Postharvest Biology and Technology, Amsterdan, v. 33, p. $11-26,2004$

MANRINQUE, G.D.; LAJOLO, F.M. FT-IR spectroscopy as a tool for measuring degree of methyl esterification in pectins isolated from ripening papaya fruit. Postharvest Biology and Technology, Amsterdan, v. 25, p. 99-107, 2002.

MEDINA, J.C.; SALOMON, E.A.G.; VIEIRA, L.F.; RENESTO, O.V.; FIGUEIREDO, N.M.S.; CANTO, W.L. Mamão: da cultura ao processamento e comercialização. Campinas: ITAL, 1980. 244p. (Série Frutas Tropicais, 7)

NASCIMENTO, J. R. O.; FABI, J. P.; CORDENUNSI, B. R.; LAJOLO, F. M. Aplicação de Differential Display e cDNA-AFLP na análise da expressão gênica durante o amadurecimento do mamão papaia $(\mathrm{Ca}$ rica papaya). In: NASCIMENTO, L.M.; NEGRI, J.D.; MATTOS JUNIOR, D. (Org.). Pós-colheita de frutas. Campinas: Instituto Agronômico e Fundag, 2008. p. 34-47.

OLIVEIRA, J. G.; CAMPOSTRINI, E.; BRESSAN-SMITH, R.; CUNHA, M. da; TORRES NETTO, A.; COSTA, E. S.; COUTINHO, K. S.; GOMES, M. M. A.; Conservação pós-colheita do mamão (Carica papaya $\mathbf{L}_{\text {.): }}$ aplicação de filmes plásticos associados à refrigeração. 1992. 41f. . Monografia (Graduação em Agronomia) - Faculdade de Ciências Agrárias e Veterinárias, Universidade Estadual Paulista, Jaboticabal, 1992.

RIVETTI, A. Conservação pós-colheita do mamão (Carica papaya L.): aplicação de filmes plásticos associados à refrigeração. 1992. 41f. . Monografia (Graduação em Agronomia) - Faculdade de Ciências Agrárias e Veterinárias, Universidade Estadual Paulista, Jaboticabal, 1992.

RUGGIERO, C. O potencial da fruticultura para o século XXI: cultura da goiaba do plantio à comercialização. Jaboticabal: Sociedade Brasileira de Fruticultura, 2009. v.1, p.13-26.
RUGGIERO, C.; DURIGAN, J. F.; NATALE, W.; OLIVEIRA, C. A. L. de; BENASSI, A. C. Mamão. In: DONADIO, L.C. (Org.). História da fruticultura paulista. Jaboticabal: Sociedade Brasileira de Fruticultura, 2010. p. 210-234

SARZI, B. Conservação de abacaxi e mamão minimamente processados: associação entre o preparo, a embalagem e a temperatura de armazenamento. 2002. 100f. Dissertação (Mestrado em Agronomia) - Faculdade de Ciências Agrárias e Veterinárias Universidade Estadual Paulista, Jaboticabal, 2001.

SERRANO, L.A.L.; CATTANEO, L.F.O cultivo do mamoeiro no Brasil. Revista Brasileira de Fruticultura, Jaboticabal, v.32, n.3, 2010. Texto de capa.

SHIGA, T.M.; FABI, J.P.; NASCIMENTO, J.R.O.; PETKOWICZ, C.L.O.; VRIESMANN, L.C.; LAJOLO, F.M.; CORDENUNSI, B.R. Changes in cell wall composition associated to the softening of ripening papaya: evidence of extensive solubilization of large molecular mass galactouronides. Journal of Agricultural and Food Chemistry, Easton, v. 57, p. 7064-7071, 2009.

TEIXEIRA, G.H.A.; DURIGAN, J.F.; MATTIUZ, B.; ROSSI JUNIOR, O.D. Processamento mínimo de mamão 'Formosa'. Ciência e Tecnologia de Alimentos, Campinas, v.21, n.1, p.47-50, 2001.

VIDIGAL, J. C.; SIGRIST, J. M. M.; SHIROSE, I.; YOKOMIZO, N.; MEDINA, J. C. Controle fitossanitário do mamão após a colheita. Boletim do ITAL, Campinas, v.16, n.4, p. 443-458, 1979.

VIDOLIN, F. C. O. Conservação pós-colheita de frutos do mamoeiro Carica papaya $\mathrm{L}$, cv Sunrise-Solo. 1984. 59f. Monografia (Graduação em Agronomia) - Faculdade de Ciências Agrárias e Veterinárias, Universidade Estadual Paulista, Jaboticabal, 1984

WARDLAW, C.W.; LEONARD, E.R. The storage and physiology of tropical fruits. Tropical Agriculture, Surrey, v.12, n.12, p.313-319, 1935. 